\title{
Neurosecretory protein GL induces fat accumulation in mice
}

\author{
Kenshiro Shikano ${ }^{1,2, *}$, Eiko Iwakoshi-Ukena ${ }^{1, *}$, Takaya Saito ${ }^{1, *}$, Yuki Narimatsu', Atsuki Kadota1, \\ Megumi Furumitsu', George E Bentley ${ }^{3}$, Lance J Kriegsfeld ${ }^{4}$ and Kazuyoshi Ukena ${ }^{1}$
}

\begin{abstract}
'Laboratory of Neuroendocrinology, Graduate School of Integrated Sciences for Life, Hiroshima University, Higashi-Hiroshima, Hiroshima, Japan 2Department of Neurophysiology, Faculty of Medicine, Oita University, Yufu, Oita, Japan

${ }^{3}$ Department of Integrative Biology and the Helen Wills Neuroscience Institute, University of California, Berkeley, California, USA

${ }^{4}$ Department of Psychology and the Helen Wills Neuroscience Institute, University of California, Berkeley, California, USA
\end{abstract}

Correspondence should be addressed to K Ukena: ukena@hiroshima-u.ac.jp

*(K Shikano, E Iwakoshi-Ukena and T Saito contributed equally to this work)

\begin{abstract}
We recently discovered a novel gene encoding a small secretory protein, neurosecretory protein GL (NPGL), which stimulates feeding behavior in mice following acute administration. These findings suggest that dysregulation of NPGL contributes to obesity and metabolic disease. To explore this possibility, we investigated the impact of prolonged exposure to NPGL through 13 days of chronic intracerebroventricular (i.c.v.) infusion and examined feeding behavior, body composition, expressions of lipid metabolic factors, respiratory metabolism, locomotor activity, and food preference. Under standard chow diet, NPGL increased white adipose tissue (WAT) mass without affecting feeding behavior and body mass. In contrast, when fed a high-calorie diet, NPGL stimulated feeding behavior and increased body mass concomitant with marked fat accumulation. Quantitative reverse transcription polymerase chain reaction (RT-PCR) analysis revealed that mRNA expressions for key enzymes and related factors involved in lipid metabolism were increased in WAT and liver. Likewise, analyses of respiratory metabolism and locomotor activity revealed that energy expenditure and locomotor activity were significantly decreased by NPGL. In contrast, selective feeding of macronutrients did not alter food preference in response to NPGL, although total calorie intake was increased. Immunohistochemical analysis revealed that NPGL-containing cells produce galanin, a neuropeptide that stimulates food intake. Taken together, these results provide further support for NPGL as a novel regulator of fat deposition through changes in energy intake and locomotor activity.
\end{abstract}

\author{
Key Words \\ - neurosecretory protein $\mathrm{GL}$ \\ - hypothalamus \\ - fat accumulation \\ - food intake \\ - energy metabolism \\ - orexigenic neuropeptide
}

\section{Introduction}

Obesity resulting from overeating and lack of exercise leads to the accumulation of triglycerides in adipocytes and increases the risk of developing metabolic syndrome (Kessler et al. 2013, Ekkekakis et al. 2016). Individuals with metabolic syndrome are at a five-fold greater risk of developing type 2 diabetes mellitus and a two-fold greater risk of developing cardiovascular disease (Alberti et al. 2009). As obesity is reaching epidemic proportions throughout the world, a better understanding of the regulatory mechanism underlying feeding behavior and 
energy metabolism is required to prevent obesity and appropriately treat patients and at-risk populations.

The regulation of feeding and metabolism is complex, and not fully understood, involving interactions among hypothalamic neuropeptides, peripheral hormones, and enzymes regulating fat and muscle accumulation. Several well-established hypothalamic factors, including the orexigenic neuropeptides, neuropeptide Y (NPY) and agouti-related peptide (AgRP), and the anorexigenic neuropeptide, $\alpha$-melanocyte-stimulating hormone $(\alpha-\mathrm{MSH})$ derived from proopiomelanocortin (POMC), play important roles in the regulation of feeding behavior (Schwartz et al. 2000). Likewise, peripheral hormones such as orexigenic ghrelin and anorexigenic leptin affect feeding via actions on hypothalamic neurons expressing these factors (Halaas et al. 1997, Nakazato et al. 2001). With regard to food preference, NPY and corticotropinreleasing hormone $(\mathrm{CRH})$ enhance carbohydrate intake (Jhanwar-Uniyal et al. 1993, Okamoto et al. 2018), while galanin (GAL) stimulates fat intake (Tempel et al. 1988). In addition to regulating food intake, NPY, AgRP, and $\alpha-\mathrm{MSH}$ regulate locomotor activity levels, further contributing to overall energy balance (Heilig \& Murison 1987, TangChristensen et al. 2004, Huo et al. 2009). Disruption in the balance between feeding and energy consumption contributes to obesity. As the current state of knowledge cannot fully account for dysregulation of energy balance resulting in obesity, other unidentified factors and/or mechanisms likely play a role in the onset and progression of metabolic disease.

As part of a search for novel hypothalamic regulatory factors, we recently discovered a novel cDNA encoding the precursor of a small secretory protein in the chicken, rat, mouse and human brain (Ukena et al. 2014, IwakoshiUkena et al. 2017, Matsuura et al. 2017, Ukena 2018). The precursor protein contains a signal peptide sequence, a mature protein sequence of 80 amino acid residues, a glycine amidation signal, and a dibasic amino acid cleavage site. Because the predicted C-terminal amino acid sequence for this small protein is Gly-Leu- $\mathrm{NH}_{2}$ (Ukena et al. 2014), it was named neurosecretory protein GL (NPGL). We have previously shown that chronic infusion of NPGL stimulates food intake and fat accumulation in rats through de novo lipogenesis (Iwakoshi-Ukena et al. 2017). Although we also established that NPGL is produced in the lateroposterior region of the hypothalamic arcuate nucleus (ArcLP) of the mouse and that acute intracerebroventricular (i.c.v.) injection of NPGL stimulates food intake in mice fed standard chow diet (Matsuura et al. 2017), the impact of chronic administration has not been examined in this species. These findings suggest that NPGL likely regulates feeding in healthy individuals and that dysregulation of NPGL contributes to overeating, fat accumulation and obesity.

Significantly, the effect of neuropeptides on food intake differs according to energy status and/or rodent species. For example, pyroglutamylated RFamide peptide (QRFP) induces a marked orexigenic effect in mice and high-fat-diet-fed rats (Takayasu et al. 2006, Primeaux et al. 2008), whereas the same peptide has minimal impact on food consumption in standard chow-fed rats (Patel et al. 2008, Primeaux et al. 2008). In addition, galanin-like peptide (GALP), an anorexigenic peptide, inhibits food intake in mice $1 \mathrm{~h}$ after acute injection, whereas GALP stimulates food consumption in rats (Krasnow et al. 2003). These findings underscore the importance of examining the effects of the same neuropeptide across rodent species to determine the generality of the findings and functional significance of the neurochemical being investigated.

The present study aimed to determine whether or not chronic infusion of NPGL affects energy metabolism, including food intake, in mice. To accomplish this goal, we first examined the impact of chronic i.c.v. infusion of NPGL on feeding behavior and body consumption in mice on a standard chow or high-calorie diet. Likewise, lipid metabolism-related genes, respiratory metabolism, and locomotor activity were quantified. Furthermore, a nutrient selection task was employed using macronutrient diets to investigate the influence of NPGL on food preference. Finally, immunohistochemical analysis was performed to survey whether NPGL-containing cells produce GAL, a food intake-stimulating factor.

\section{Materials and methods}

\section{Animals}

Male C57BL/6J mice (7 weeks old) were purchased from Charles River Laboratories and housed in standard laboratory conditions $\left(25 \pm 1^{\circ} \mathrm{C}\right.$ under a 12 -h light/12-h dark cycle) with ad libitum access to water and standard laboratory chow (CE-2, pellet; CLEA Japan, Tokyo, Japan) or a high-calorie diet (32\% of calories from fat $/ 20 \%$ of calories from sucrose, D14050401, pellet; Research Diets). In a food preference experiment, macronutrient diets were given at the same time in three feed boxes which contained a protein diet $(98.5 \%$ of calories from casein $1.5 \%$ of calories from L-cystine, D14082901, powder; Research Diets), a carbohydrate diet (43.6\% of calories from corn starch $/ 40.6 \%$ of calories from sucrose $/ 15.8 \%$ calories from 
maltodextrin 10, D14082902, powder; Research Diets), and a fat diet (92.2\% of calories from lard/7.8\% of calories from soy bean oil, D14082903, powder; Research Diets) and food intake for each diet was measured every day.

All animal experiments were performed according to the Guide for the Care and Use of Laboratory Animals prepared by Hiroshima University (Higashi-Hiroshima, Japan) and these procedures were approved by the Institutional Animal Care and Use Committee of Hiroshima University (permit numbers: C11-2, C13-12, and C13-17).

\section{Production of NPGL}

NPGL containing 80 amino acid residues, identical to the mouse NPGL sequence, was synthesized by microwaveassisted solid-phase peptide synthesis using an automated peptide synthesizer (Syro Wave; Biotage, Uppsala, Sweden) as previously described (Masuda et al. 2015).

\section{Chronic i.c.v. infusion}

For the 13-day chronic i.c.v. infusion of NPGL, infusion cannulae (28 gauge, 3280P; Plastics One, Roanoke, VA, USA) were unilaterally inserted into the left lateral ventricle in 8-week-old mice. The final coordinates of the cannula tips were as follows: $0.2 \mathrm{~mm}$ caudal to bregma, $1.0 \mathrm{~mm}$ lateral to midline, and $2.25 \mathrm{~mm}$ ventral to the skull surface. NPGL (3.75 nmol/day) was dissolved in 30\% propylene glycol and adjusted to $\mathrm{pH} 8.0$ with $\mathrm{NaOH}$. For control animals, the vehicle solution was employed. The dose of NPGL was adjusted for average mouse brain mass (approximately $1 / 4$ that of rats) based on our previous findings in rats where $15 \mathrm{nmol} /$ day was applied (IwakoshiUkena et al. 2017). In our previous work, this dose was found to effectively increase WAT mass and adipocyte size in rats (Iwakoshi-Ukena et al. 2017).

The solutions were loaded into an ALZET mini-osmotic pump (delivery rate: $0.25 \mu \mathrm{l} / \mathrm{h}$, model 1002; DURECT Co., Cupertino, CA, USA) connected to the infusion cannula using polyethylene tubing a day before surgery and kept overnight at $37^{\circ} \mathrm{C}$. On the day of cannula insertion, the osmotic pump was implanted subcutaneously into the back. We confirmed that the infusion was accurate by examining the solution remaining in the pump at the endpoint. The administration period of NPGL was fixed to 13 days because insolubility of NPGL increased in the pump over 2 weeks.

Food intake and body mass were measured every day. The mass of inguinal, epididymal, retroperitoneal, and perirenal white adipose tissue (WAT) was measured at the endpoint in all experiments. The masses of interscapular brown adipose tissue (BAT), liver, heart, kidney, testis, and gastrocnemius muscle were also measured at the endpoint in all experiments.

\section{Real-time RT-PCR}

Inguinal WAT (iWAT), epididymal WAT (eWAT), retroperitoneal WAT (rWAT), the liver, and the hypothalamus were dissected from mice and snap frozen in liquid nitrogen for RNA processing at the conclusion of the NPGL infusion. Total RNA was extracted using QIAzol lysis reagent for WAT (Qiagen) or TRIzol reagent for the liver and the hypothalamus (Life Technologies) in accordance with the manufacturer's instructions. Firststrand cDNA was synthesized from total RNA using a ReverTra Ace kit (Toyobo, Osaka, Japan).

The abbreviations for genes and sequences of primers used in this study are listed in Tables 1 and 2, respectively. PCR amplifications were conducted with THUNDERBIRD SYBR qPCR Mix (Toyobo) using the following conditions: $95^{\circ} \mathrm{C}$ for $20 \mathrm{~s}$, followed by 40 cycles of $95^{\circ} \mathrm{C}$ for $3 \mathrm{~s}$, and $60^{\circ} \mathrm{C}$ for $30 \mathrm{~s}$. The PCR products in each cycle were monitored using a Bio-Rad CFX Connect (Bio-Rad Laboratories). Relative quantification of each gene was determined by

Table 1 Abbreviations.

\begin{tabular}{ll}
\hline Gene & Name \\
\cline { 1 - 2 } Acc & Acetyl-CoA carboxylase \\
Fas & Fatty acid synthase \\
Scd1 & Stearoyl-CoA desaturase 1 \\
Chrebp $\alpha$ & $\begin{array}{l}\text { Carbohydrate-responsive element-binding } \\
\text { protein } \alpha\end{array}$ \\
Chrebp $\beta$ & Carbohydrate-responsive element-binding \\
& protein $\beta$ \\
Cpt1a & Carnitine palmitoyl transferase 1a \\
Atgl & Adipose triglyceride lipase \\
Hsl & Hormone-sensitive lipase \\
Fgf21 & Fibroblast growth factor 21 \\
Gapdh & Glyceraldehyde 3-phosphate dehydrogenase \\
Slc2a2 & Solute carrier family 2 member 2 \\
Slc2a4 & Solute carrier family 2 member 4 \\
Cd36 & Cluster of differentiation 36 \\
Ppar $\alpha$ & Peroxisome proliferator-activated receptor $\alpha$ \\
Ppar & Peroxisome proliferator-activated receptor $\gamma$ \\
Pgc1 $\alpha$ & Peroxisome proliferator-activated receptor $\gamma$ \\
Tnf $\alpha$ & Coactivator 1 $\alpha$ \\
Npy & Tumor necrosis factor $\alpha$ \\
Agrp & Neuropeptide Y \\
Pomc & Agouti-related peptide \\
Gal & Proopiomelanocortin \\
Rps18 & Galanin \\
Actb & Ribosomal protein S18 \\
\hline & B-Actin \\
\hline
\end{tabular}


Table 2 Sequences of oligonucleotide primers for real-time RT-PCR.

\begin{tabular}{l}
\hline Gene \\
\hline Acc \\
Fas \\
Scd1 \\
Chrebp $\alpha$ \\
Chrebp $\beta$ \\
Cpt1a \\
Atgl \\
Hsl \\
Fgf21 \\
Gapdh \\
Slc2a2 \\
Slc2a4 \\
Cd36 \\
Ppara \\
Ppary \\
Pgc1 \\
Tnfo \\
Npy \\
Agrp \\
Pomc \\
Gal \\
Rps18 \\
Actb \\
\hline
\end{tabular}

\begin{tabular}{l} 
sense primer $\left(5^{\prime}\right.$ to $\left.3^{\prime}\right)$ \\
\hline TCCGCACTGACTGTAACCACAT \\
AGGGGTCGACCTGGTCCTCA \\
CTGTACGGGATCATACTGGTTC \\
CGACACTCACCCACCTCTTC \\
TCTGCAGATCGCGTGGAG \\
CCTGGGCATGATTGCAAAG \\
AACACCAGCATCCAGTTCAA \\
GCTGGGCTGTCAAGCACTGT \\
CCTCTAGGTTTCTTTGCCAACAG \\
AAGGTCATCCCAGAGCTGAA \\
GGCTAATTTCAGGACTGGTT \\
GTAACTTCATTGTCGGCATGG \\
TCCTCTGACATTTGCAGGTCTATC \\
TCGAATATGTGGGGACAAGG \\
GCCCTTTGGTGACTTTATGGA \\
GCAACATGCTCAAGCCAAAC \\
GCCTCTTCTCATTCCTGCTTG \\
TATCTCTGCTCGTGTGTTTG \\
TGTTCCCAGAGTTCCCAGGTC \\
AGCTGCCTTTCCGCGACA \\
GAGCCTTGATCCTGCACTGA \\
CCTGAGAAGTTCCAGCACAT \\
GGCACCACACCTTCTACAAT
\end{tabular}

Antisence primer (5' to 3')

TGCTCCGCACAGATTCTTCA

GCCATGCCCAGAGGGTGGTT

GCCGTGCCTTGTAAGTTCTG

TTGTTCAGCCGGATCTTGTC

CTTGTCCCGGCATAGCAAC

GGACGCCACTCACGATGTT

GGTTCAGTAGGCCATTCCTC

GTAACTGGGTAGGCTGCCAT

AAGCTGCAGGCCTCAGGAT

CTGCTTCACCACCTTCTTGA

TTTCTTTGCCCTGACTTCCT

AGCTGAGATCTGGTCAAACG

AAAGGCATTGGCTGGAAGAA

GACAGGCACTTGTGAAAACG

GCAGCAGGTTGTCTTGGATG

TGCAGTTCCAGAGAGTTCCA

CTGATGAGAGGGAGGCCATT

GATTGATGTAGTGTCGCAGA

GCATTGAAGAAGCGGCAGTAGCAC

ATCTATGGAGGTCTGAAGCA

AGTGGCTGACAGGGTCACAA

TTCTCCAGCCCTCTTGGTG

AGGTCTCAAACATGATCTGG

the $2^{-\Delta \Delta \mathrm{Ct}}$ method using ribosomal protein S18 (Rps18) for WAT or $\beta$-actin $(A c t b)$ for the liver and the hypothalamus as internal controls (Livak \& Schmittgen 2001).

\section{Indirect calorimetry and locomotor activity}

Six to twelve days after infusion of NPGL, indirect calorimetry was performed using an $\mathrm{O}_{2} / \mathrm{CO}_{2}$ metabolismmeasuring system for small animals (MK-5000RQ; Muromachi Kikai, Tokyo, Japan). The system monitored $\mathrm{VO}_{2}(\mathrm{~mL} / \mathrm{min})$ and $\mathrm{VCO}_{2}(\mathrm{~mL} / \mathrm{min})$ at 3-min intervals and calculated respiratory quotient (RQ) ratio $\left(\mathrm{VCO}_{2} /\right.$ $\mathrm{VO}_{2}$ ). Locomotor activity was simultaneously measured using the SUPERMEX infrared ray passive sensor system (Muromachi Kikai). After a 30-min habituation period, measurements were collected hourly for the next $23 \mathrm{~h}$ (light period: 10:00-21:00, dark period: 21:00-09:00). Energy expenditure was calculated using the following equation: energy expenditure $(\mathrm{cal} / \mathrm{kg} / \mathrm{h})=\mathrm{VO}_{2}(\mathrm{~mL} / \mathrm{kg} / \mathrm{h}) \times$ $(3.815+(1.232 \times \mathrm{RQ}))($ Lusk 1928) .

\section{Hematoxylin and eosin staining}

For paraffin embedding, eWAT was fixed with a $4 \%$ paraformaldehyde solution for 2 days and delipidated with xylene and ethanol. The tissues were embedded in paraffin and sectioned to a thickness of $7 \mu \mathrm{m}$ with a microtome. The paraffin tissue sections were deparaffinized with xylene and graded ethanol, stained with hematoxylin and eosin (5 min for each stain) and microscopic examination was performed using a Nikon Eclipse E600 conventional microscope (Nikon).

\section{Oil Red O staining}

To detect fat accumulation in the liver, the liver was fixed in $4 \%$ paraformaldehyde and sliced into $10 \mu \mathrm{m}$ sections. Sections were air-dried, rinsed with 60\% isopropanol, stained with Oil Red $\mathrm{O}$ solution for $15 \mathrm{~min}$ at $37^{\circ} \mathrm{C}$, and rinsed with $60 \%$ isopropanol. Nuclei were counterstained with hematoxylin for $5 \mathrm{~min}$ and sections were then washed in tap water. Coverslips were applied using aqueous mounting medium.

\section{Immunohistochemistry}

Colchicine was injected into the lateral ventricle $(30 \mu \mathrm{g} / 2.5 \mu \mathrm{L})$ of male mice (8 weeks old). After 2 days, the brains were cut into $20 \mu \mathrm{m}$ sections with a cryostat at $-20^{\circ} \mathrm{C}$ following cryoprotection and freezing. Immunofluorescent staining on free-floating sections was conducted as described previously (Matsuura et al. 2017). Briefly, the sections were incubated in blocking buffer (1\% BSA, 1\% normal donkey serum and 0.3\% Triton $\mathrm{X}-100$ in $10 \mathrm{mM}$ PBS) for $1 \mathrm{~h}$ at room temperature before incubating with the primary antibodies. The relationship 
between NPGL-immunoreactive cells and GAL neurons was surveyed using double-label immunofluorescence as follows: a rabbit antibody against NPGL (1:100 dilution) and a guinea pig antibody raised against porcine GAL (1:4,000 dilution, T-5036; Peninsula Laboratories, San Carlos, CA, USA) were used for the detection of NPGL and GAL staining, respectively. Cy3-conjugated donkey anti-rabbit IgG (1:600 dilution, 711-165-152; Jackson ImmunoResearch) and Alexa Fluor 488-conjugated donkey anti-guinea pig IgG (1:600 dilution, 706-545-148, Jackson ImmunoResearch) were used as secondary antibodies. Immunoreactive labeling was observed using a Nikon Eclipse E600 conventional microscope (Nikon) or an Olympus FV1000 confocal microscope (Olympus).

\section{Blood chemistry}

Serum levels of glucose and lipids were measured using standard equipment, reagents, and kits. The GLUCOCARD $\mathrm{G}+$ meter was used to measure glucose content (Arkray, Kyoto, Japan). The Triglyceride E-Test Wako (Wako Pure Chemical Industries) was used to measure triglyceride levels and the Cholesterol E-Test Wako (Wako Pure Chemical Industries) to measure cholesterol content.

\section{Statistics}

Group differences between NPGL and vehicle-treated animals were assessed using Student's $t$-tests for tissue mass, mRNA expression, respiratory metabolism, and locomotor activity or a two-way ANOVA followed by Bonferroni's test as appropriate for food intake and body mass. $P$ values of $<0.05$ were considered statistically significant.

\section{Results}

\section{Effect of NPGL on food intake and body composition under normal chow}

Chronic i.c.v. infusion of NPGL $(3.75 \mathrm{nmol} /$ day $)$ was performed using osmotic pumps in mice fed standard chow. Food intake was measured during the light and dark periods and body composition, including body mass, was recorded. Although no changes in food intake (24 h, or during light and dark periods) and body mass were observed (Fig. 1A and B, and Supplementary Fig. $1 \mathrm{~A}$, see section on supplementary materials given at the end of this article), epididymal, retroperitoneal, and perirenal WAT masses increased significantly (Fig. 1C). By contrast, interscapular BAT, liver, heart, kidney, testis, and gastrocnemius muscle masses remained unchanged (Supplementary Fig. 2). There were no significant differences in the levels of glucose, triglycerides, and cholesterol in the blood (Table 3).

\section{Effect of NPGL on food intake and body composition under high calorie diet}

To determine whether the impact of NPGL is altered by diet composition, animals fed a high caloric diet were examined while NPGL was infused. Under these conditions, food intake ( $24 \mathrm{~h}$ or during the light period) and body mass were markedly increased after chronic infusion of NPGL relative to vehicle-treated mice (Fig. 1D and E, and Supplementary Fig. 1B). Likewise, NPGL significantly increased WAT mass compared to controls (Fig. 1F and Supplementary Fig. 3A). In addition, interscapular BAT mass was also significantly increased by NPGL (Fig. 2A and Supplementary Fig. 3B).
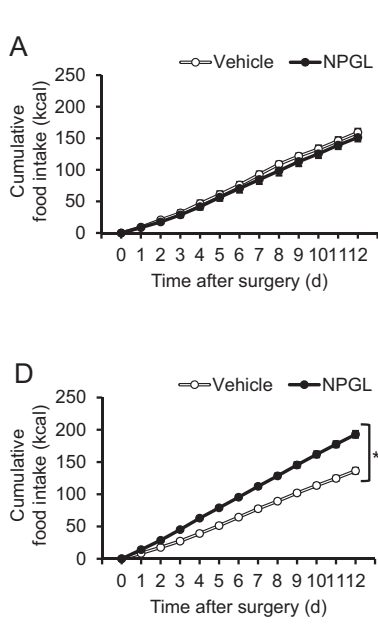
https://doi.org/10.1530/JOE-19-0112
Standard Chow Diet
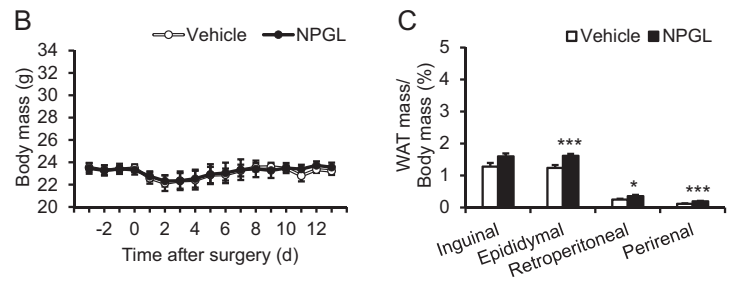

High Calorie Diet
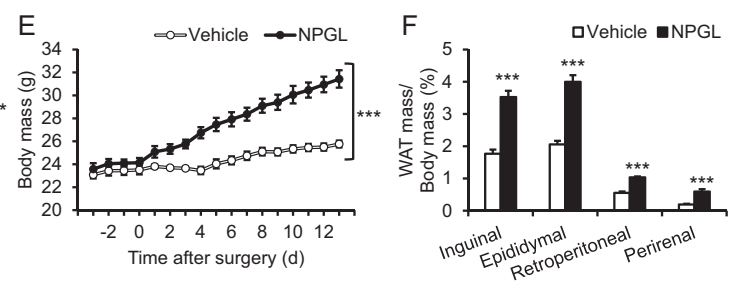

Figure 1

Effect of chronic intracerebroventricular infusion of vehicle or neurosecretory protein GL (NPGL) (3.75 nmol/day) on food intake, body mass, and white adipose tissue (WAT) in animals fed standard chow (A, B and $C, n=8)$ and a high calorie diet (D, E and F, $n=6-8$ ). (A and D) Cumulative food intake. ( $\mathrm{B}$ and $\mathrm{E}$ ) Body mass. ( $C$ and F) Ratio of inguinal, epididymal, retroperitoneal, and perirenal WAT mass/body mass. Each value represents the mean \pm standard error of the mean. $* P<0.05, * * * P<0.005$. 
Table 3 Blood chemistry during i.c.v. infusion of NPGL under three different diets.

\begin{tabular}{|c|c|c|}
\hline & \multicolumn{2}{|c|}{ Standard chow diet } \\
\hline & Vehicle & NPGL \\
\hline Glucose (mg/dL) & $154 \pm 6.2$ & $149 \pm 4.9$ \\
\hline Triglycerides (mg/dL) & $100 \pm 8.8$ & $102 \pm 9.0$ \\
\hline Cholesterol (mg/dL) & $90 \pm 5.6$ & $108 \pm 5.0$ \\
\hline
\end{tabular}

In contrast, heart, testis, and gastrocnemius muscle masses were decreased by NPGL administration, whereas no changes were observed in the liver and kidney (Fig. 2B and C). Histological examinations of lipid deposition in WAT, using hematoxylin and eosin staining, and the liver, using Oil Red O staining, revealed that lipid droplets were observed in both tissues after NPGL infusion (Supplementary Fig. 3C and D). Finally, levels of cholesterol in the blood increased significantly after NPGL infusion (Table 3).

\section{Effect of NPGL on mRNA expression of lipid metabolism-related genes}

In order to investigate the cause of fat accumulation by NPGL, we analyzed the expression of several enzymes and related factors (i.e., lipogenesis and lipolysis) in iWAT as subcutaneous adipose tissue, rWAT as visceral adipose tissue, and liver under standard chow and highcalorie diet conditions. Under standard chow, mRNA expression levels of carnitine palmitoyl transferase $1 \mathrm{a}$ (CPT1a), a lipolytic enzyme, and glyceraldehyde-3phosphate dehydrogenase (GAPDH), a carbohydrate metabolic enzyme, increased in the rWAT and liver, respectively (Supplementary Fig. 4).

In contrast, when fed a high-calorie diet, mRNA expression levels of stearoyl-CoA desaturase 1 (SCD1), a lipogenesis enzyme, and CPT1a increased in iWAT (Fig. 3A). In rWAT, cluster of differentiation 36 (CD36), a fatty acid transporter, and tumor necrosis factor $\alpha(\mathrm{TNF} \alpha)$, an inflammatory cytokine, also increased in addition to SCD1 and CPT1a (Fig. 3B). In the liver, carbohydrateresponsive element-binding protein $\alpha$ (ChREBP $\alpha)$, a lipogenic transcription factor, GAPDH, solute carrier family 2 member 2 (SLC2A2), a glucose transporter known as GLUT2, CD36, and peroxisome proliferator-activated receptor $\gamma(\operatorname{PPAR} \gamma)$, a lipid-activated transcription factor, were upregulated (Fig. 3C).

\section{Effect of NPGL on respiratory metabolism and locomotor activity}

To analyze whole body respiratory metabolism, we measured $\mathrm{VO}_{2}$ and $\mathrm{VCO}_{2}$ 6-12 days after NPGL infusion under both standard chow and high-calorie diet feeding conditions. Under standard chow feeding, $\mathrm{VO}_{2}$ decreased during the dark period without changes in $\mathrm{VCO}_{2}$ (Fig. $4 \mathrm{~A}$ and $\mathrm{B})$. In addition, overall energy expenditure also decreased during the dark period (Fig. 4C). However, the RQ ratio remained unchanged (Supplementary Fig. 5A). Furthermore, locomotor activity significantly decreased during the dark period (Fig. 4D).

Under high-calorie diet feeding, $\mathrm{VO}_{2}$ was significantly decreased during the dark period and $\mathrm{VCO}_{2}$ during the light period in NPGL-infused mice (Fig. 5A and B). Overall energy expenditure also decreased during the light and dark periods (Fig. 5C), although the RQ ratio did not change (Supplementary Fig. 5B). Locomotor activity also significantly decreased during the dark period in response to NPGL (Fig. 5D).

\section{Effect of NPGL on food preference}

As mentioned previously, NPGL stimulated food intake in mice fed a high-calorie diet without affecting food
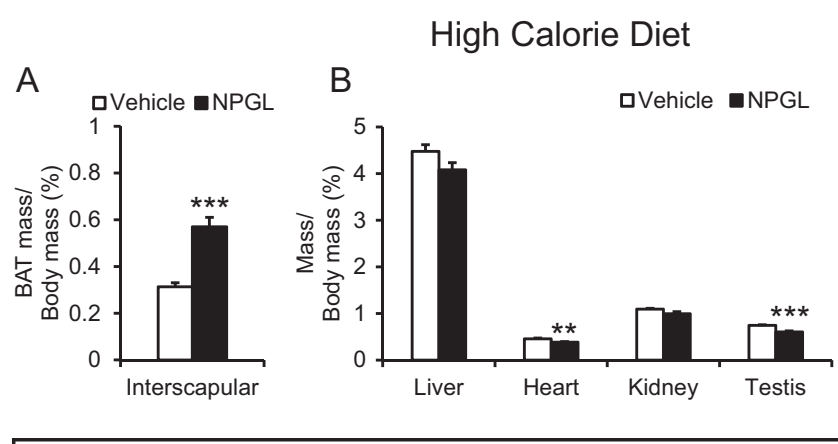

https://joe.bioscientifica.com https://doi.org/10.1530/JOE-19-0112
(C) 2020 Society for Endocrinology Published by Bioscientifica Ltd.
Printed in Great Britain

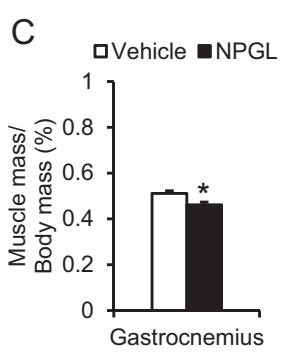

Figure 2

Effect of chronic intracerebroventricular infusion of vehicle or neurosecretory protein GL (NPGL) ( $3.75 \mathrm{nmol} /$ day) on body composition in animals fed a high calorie diet $(n=6-8)$. (A) Ratio of interscapular brown adipose tissue (BAT) mass/ body mass. (B) Ratio of liver, heart, kidney, and testis mass/body mass. (C) Ratio of gastrocnemius muscle mass/body mass. Each value represents the mean \pm standard error of the mean. $* P<0.05$, $\star \star P<0.01, * \star * P<0.005$. 
High Calorie Diet
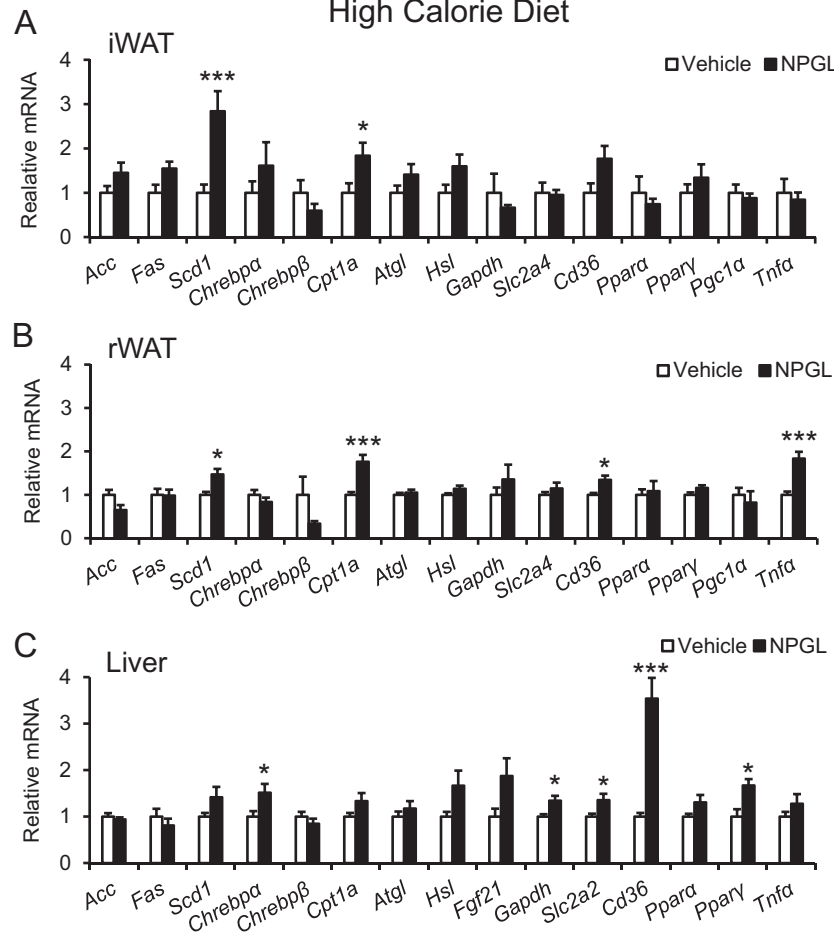

Figure 3

Effect of the chronic intracerebroventricular infusion of vehicle or neurosecretory protein GL (NPGL) $(3.75 \mathrm{nmol} /$ day) on the mRNA expressions of lipid metabolism-related genes in animals fed a high calorie diet $(n=6-8)$. mRNA expression levels for inguinal WAT (iWAT) (A), retroperitoneal WAT (rWAT) (B), and liver (C). Each value represents the mean \pm standard error of the mean. ${ }^{*} P<0.05, * \star \star P<<0.005$

intake in mice fed standard chow. As the high-calorie diet includes high levels of sucrose (as the carbohydrate source) and fat, we hypothesized that NPGL may affect food preference for sucrose or fat. To investigate the effect of NPGL on carbohydrate and fat intake, the caloric value of each nutrient was examined using ad libitum selective feeding of macronutrient diets, that is, three different powder diets of protein, carbohydrate, and fat.

Mice infused with NPGL had higher total caloric intake compared to vehicle-treated animals (Fig. 6A and Supplementary Fig. 6). In addition, cumulative fat intake tended to increase during the NPGL infusion (Fig. 6A). Likewise, NPGL increased WAT mass without significantly changing body mass (Fig. 6B and C, and Supplementary Fig. 7A). Although liver mass remained unchanged (Fig. 6D), fatty liver was observed after chronic infusion of NPGL (Supplementary Fig. 7B). The levels of glucose and triglycerides in the blood increased significantly after NPGL infusion (Table 3). In addition, SCD1 and ChREBP $\alpha$ mRNA expression was upregulated in eWAT and liver, respectively (Supplementary Fig. 8).

\section{Co-localization of NPGL and GAL in the same cells}

As indicated earlier, analyses using standard chow, high-calorie diet, and macronutrient diets, reveal that NPGL stimulates food intake. As a result, we surveyed the morphological relationship between NPGL and GAL, a fat intake-regulating neuropeptide in the ArcLP of the hypothalamus, using immunohistochemistry. Approximately 30\% NPGL-containing cells were found to produce GAL in the ArcLP of the hypothalamus (Fig. 7).

\section{Effect of NPGL on mRNA expression of neuropeptide genes}

To examine the impact of NPGL at the level of the hypothalamus after chronic i.c.v. infusion, we analyzed the mRNA expression for several neuropeptides (NPY, AgRP, POMC, and GAL) in the hypothalamus under highcalorie diet conditions. Among these factors, NPY mRNA expression was downregulated in the hypothalamus (Supplementary Fig. 9).

\section{Discussion}

We have previously shown that NPGL is specifically expressed in the hypothalamus of chickens, rats, and mice (Ukena et al. 2014, Iwakoshi-Ukena et al. 2017, Matsuura et al. 2017, Ukena 2018) and participates in energy metabolism in chicks and rats (Iwakoshi-Ukena et al. 2017, Shikano et al. 2018, 2019). In mice, we found that acute i.c.v. injection of NPGL stimulated food intake and this effect was sustained for at least $8 \mathrm{~h}$ under standard chow diet (Matsuura et al. 2017). However, the effect of chronic NPGL has not been examined in this species. As a result, the present series of experiments examined the chronic effects of NPGL on feeding behavior and energy metabolism in mice. Consistent with our previous studies in rats (Iwakoshi-Ukena et al. 2017), the present findings revealed that NPGL increases fat (i.e., WAT) accumulation without changes in food intake and body mass when animals are fed standard laboratory chow. In contrast, NPGL markedly stimulates food intake and body mass when mice are fed a high-calorie diet. In WAT, NPGL induces hypertrophy in adipocytes although hyperplasia remains to be explored. In rats, NPGL negligibly increased food intake and body mass under a high-calorie diet (Iwakoshi-Ukena et al. 2017). Likewise, mRNA expression for factors regulating lipid metabolism were increased by NPGL in WAT and liver in animals fed a high-calorie diet. In addition, energy consumption and locomotor 
Endocrinology

mice

\section{Standard Chow Diet}
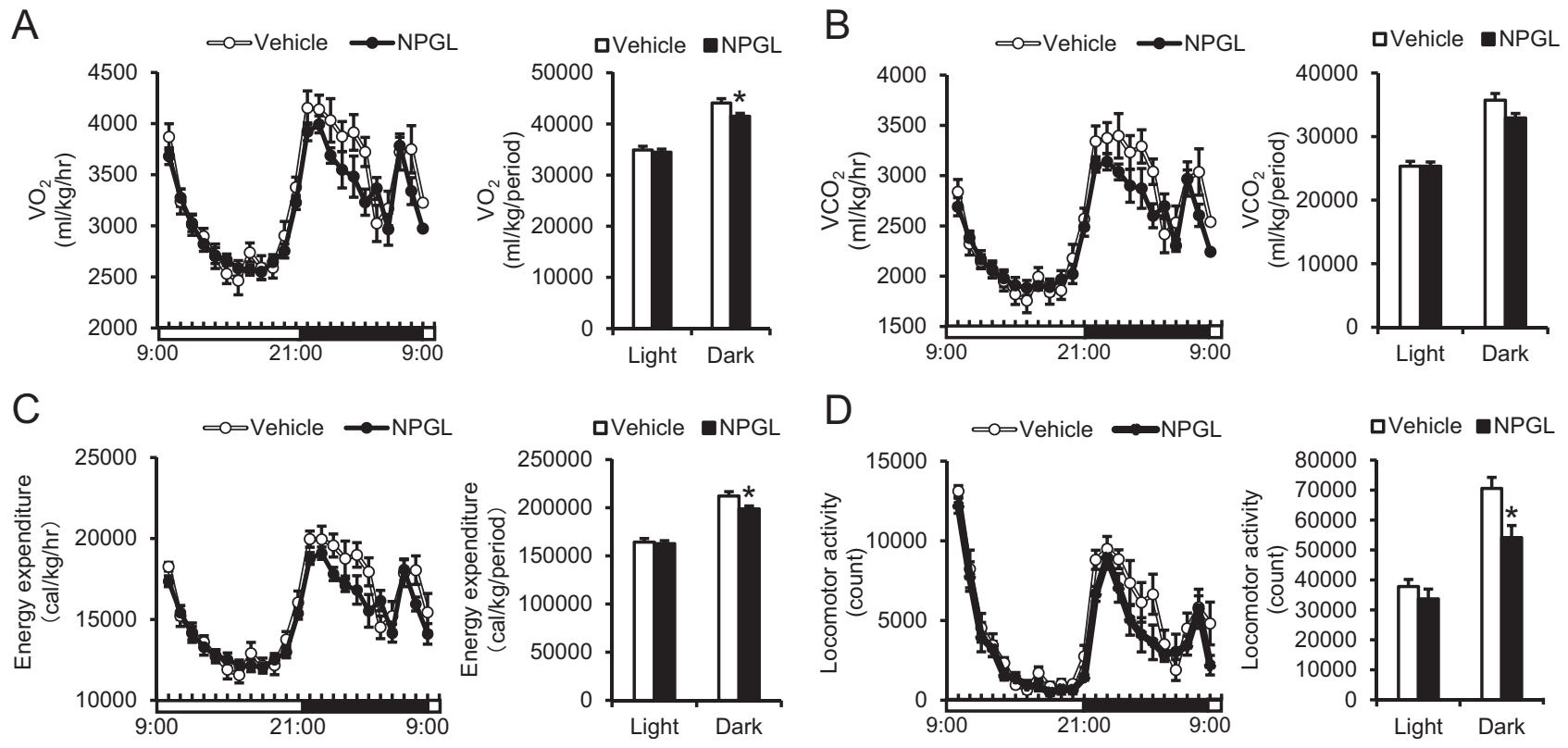

Figure 4

Effect of the chronic intracerebroventricular infusion of vehicle or neurosecretory protein GL (NPGL) (3.75 nmol/day) on respiratory metabolism and locomotor activity in animals fed standard chow. (A) $\mathrm{O}_{2}$ consumption $\left(\mathrm{VO}_{2}\right)$ measured in the metabolic chamber $(n=7-8)$. (B) $\mathrm{CO}_{2}$ production $(\mathrm{VCO})_{2}$ measured in a metabolic chamber $(n=7-8)$. (C) Energy expenditure ( $n=7-8)$. (D) Spontaneous locomotor activity measured by a passive infrared sensor $(n=6-8)$. Each value represents the mean \pm standard error of the mean. ${ }^{*} p<0.05$.

\section{High Calorie Diet}
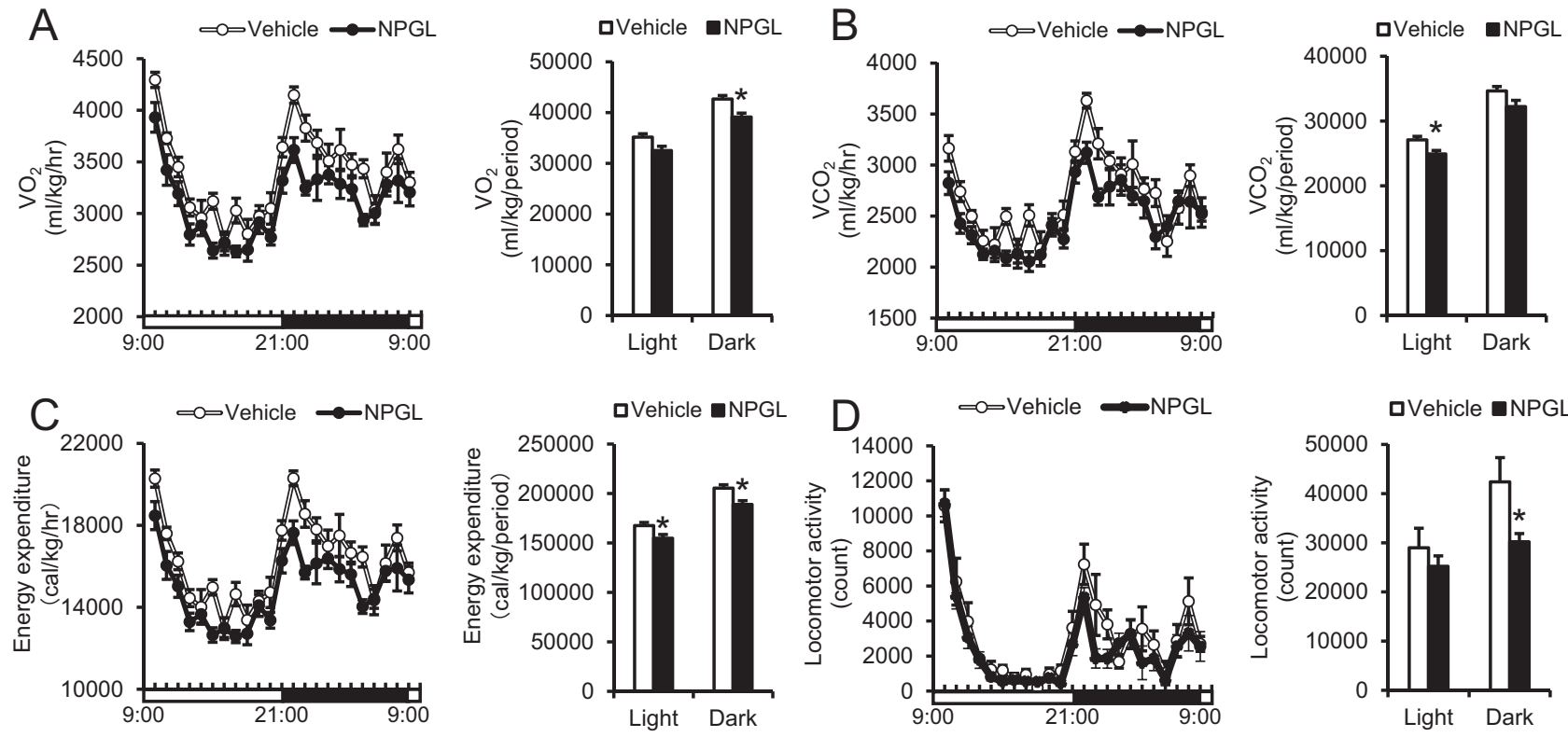

Figure 5

Effect of chronic intracerebroventricular infusion of vehicle or neurosecretory protein GL (NPGL) (3.75 nmol/day) on respiratory metabolism and spontaneous locomotor activity in animals fed a high-calorie diet $(n=5-6)$. (A) $\mathrm{O}_{2}$ consumption $\left(\mathrm{VO}_{2}\right)$ measured in the metabolic chamber. (B) $\mathrm{CO}_{2}$ production $\left(\mathrm{VCO}_{2}\right)$ measured in the metabolic chamber. (C) Energy expenditure. (D) Spontaneous locomotor activity measured by a passive infrared sensor. Each value represents the mean \pm standard error of the mean. ${ }^{\star} P<0.05$. 


\section{Macronutrient Diets}
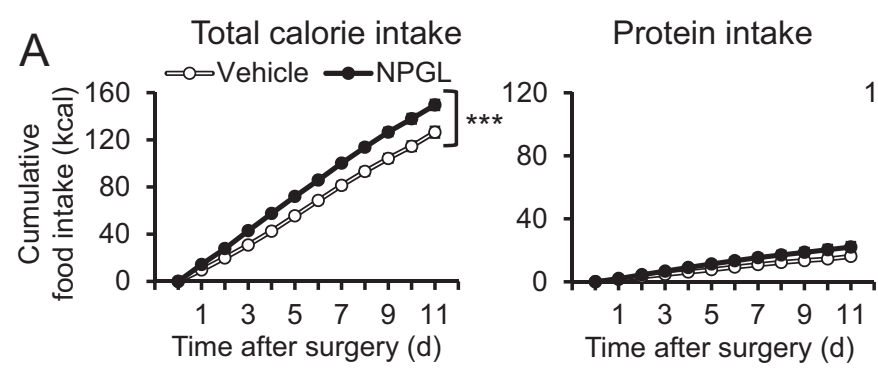

Carbohydrate intake

Fat intake

B
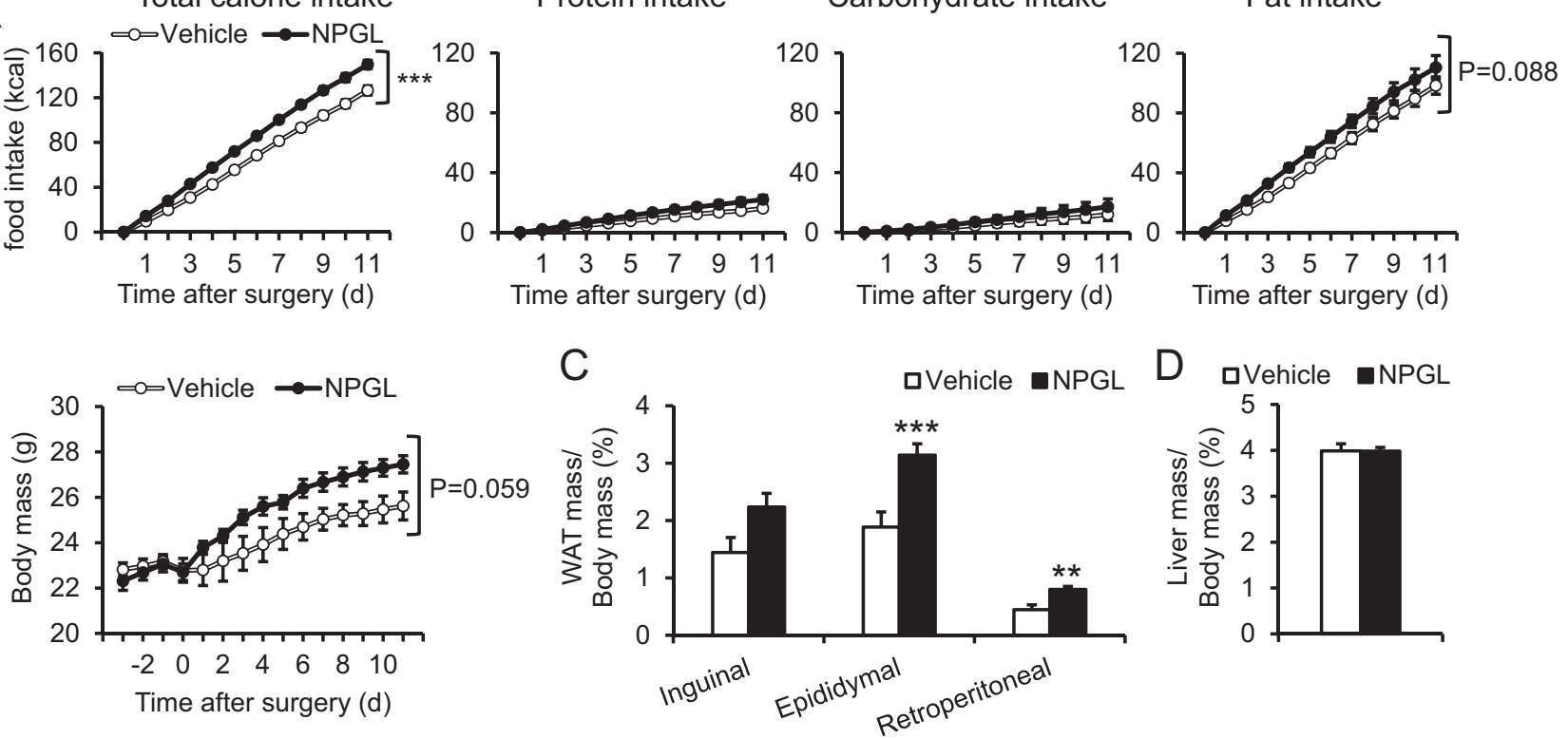

Figure 6

Effect of chronic intracerebroventricular infusion of vehicle or neurosecretory protein GL (NPGL) (3.75 nmol/day) on food intake and body composition in animals fed macronutrient diets $(n=6-7)$. (A) Cumulative food intake of macronutrient diets (total, protein, carbohydrate, and fat). (B) Body mass. (C) Ratio of inguinal, epididymal, and retroperitoneal WAT mass/body mass. (D) Ratio of liver mass/body mass. Each value represents the mean \pm standard error of the mean. ${ }^{*} * P<0.01, * \star \star x<0.005$.

activity were decreased by NPGL infusion even in mice fed standard chow, contrasting with previous findings in rats (Iwakoshi-Ukena et al. 2017). In rats, RQ values were increased by NPGL without a significant difference in energy consumption and locomotor activity (IwakoshiUkena et al. 2017). Taken together, these results suggest that NPGL promotes fat accumulation in mice due to reductions in energy consumption and locomotor activity, particularly during the dark period when mice are more active. Under a high-calorie diet, NPGL stimulates food intake, further contributing to the onset of obesity.

We previously found that acute ( 1 min) i.c.v. injection of $1 \mathrm{nmol}$ of NPGL-stimulated food intake in mice fed standard chow (Matsuura et al. 2017). Acute i.c.v. injections of NPY and ghrelin, powerful feeding promoting factors, stimulate feeding behavior at lower concentrations than NPGL (Morley et al. 1987, Iyengar et al. 1999, Wren et al. 2000), suggesting that the food intake-stimulating efficiency of NPGL may not be as pronounced as that of NPY and ghrelin in animals fed standard chow. In contrast to previous findings applying acute NPGL administration, in the present study, infusion of $3.75 \mathrm{nmol} /$ day of NPGL did not affect food intake in mice fed standard chow. This difference may be due to the different doses employed in the present and previous investigation. Also of note, whereas acute i.c.v. injection of melanin-concentrating hormone $(\mathrm{MCH})$, an established orexigenic factor, stimulates feeding behavior in animals fed standard chow diets (Rossi et al. 1999), food intake remains unchanged after chronic i.c.v. infusion of $\mathrm{MCH}$, while fat mass is increased (Gomori et al. 2003). Thus, differences in the impact of NPGL on feeding in animals fed standard chow likely result from the extent of administration. However, it would be beneficial to examine dose-dependent effects of NPGL in future studies as possible causes for differential responses observed.

In contrast to results obtained from mice fed standard chow, NPGL stimulated food intake in animals fed a high-calorie diet. In addition, NPGL increased total caloric intake under macronutrient diets. Furthermore, cumulative fat intake tended to increase during the NPGL infusion. This result suggests that NPGL may mediate fat intake in mice. As GAL is known to enhance food intake, including fat intake (Tempel et al. 1988), we investigated whether NPGL cells also produce GAL. Indeed, the present results showed that a substantial proportion of cells produce both NPGL and GAL, suggesting that these cells are involved in the stimulation of food intake. Additionally, because high-fat diets impact the reward system in addition to dietary preference 
A

Bregma $-2.53 \mathrm{~mm}$
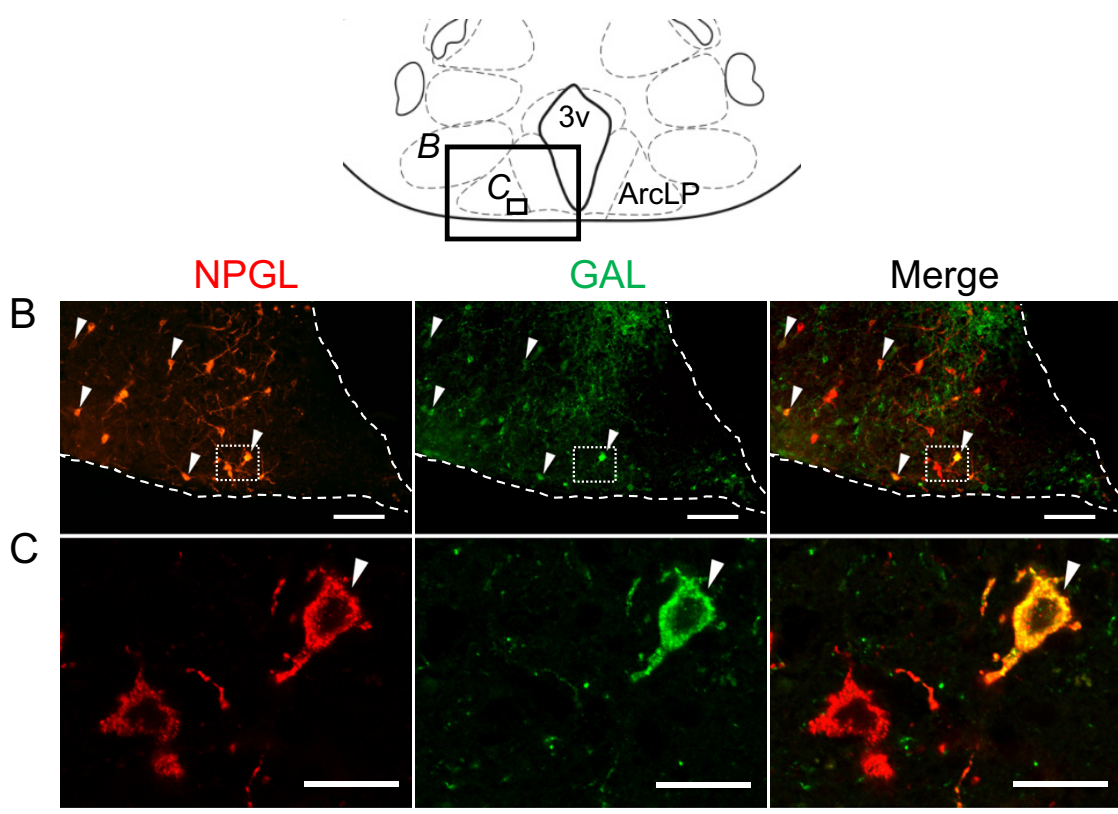

\section{Figure 7}

A subset of neurosecretory protein GL (NPGL) cells express galanin (GAL). The regions in the photomicrographs ( $B$ and $C$ ) depicted in the schematic illustration (A) are shown. The distribution of NPGL-immunoreactive cells and GAL-immunoreactive cells in the lateroposterior region of the arcuate nucleus (ArCLP) near the third ventricle (3v) using conventional microscopy (B) or confocal microscopy (C). The dotted rectangles in $B$ are shown magnified in $C$. Arrowheads in B and C indicate cells labeled for both NPGL and GAL. Scale bars $=100 \mu \mathrm{m}$ in B and $10 \mu \mathrm{m}$ in $\mathrm{C}$.

(Teegarden et al. 2009), further studies are needed to explore the impact of NPGL on mesocorticolimbic reward circuitry.

We have recently found that NPGL induces fat accumulation due to increased de novo lipogenesis in WAT, but not in the liver, of rats (Iwakoshi-Ukena et al. 2017). However, we did not observe an effect of NPGL on this same pathway in mice in the present study. Specifically, acetyl-CoA carboxylase (ACC), fatty acid synthase (FAS), ChREBP $\alpha$, and SLC2A4 (GLUT4) mRNA expression, which participate de novo lipogenesis (Ameer et al. 2014), did not increase in WAT of mice given NPGL relative to controls (Fig. 3A and B). In contrast to results seen in WAT, mRNA expression for some factors associated with lipid synthesis and uptake, including ChREBP $\alpha$, GAPDH, SLC2A2 (GLUT2), and CD36 were increased by NPGL infusion in the liver (Fig. 3C). Furthermore, the fact that mice fed a highcalorie diet and macronutrient diets developed fatty livers (Supplementary Figs 3D and 7B) indicates that fat synthesis and uptake occur primarily in the liver. It is well established that increased de novo lipogenesis in subcutaneous WAT facilitates metabolism and excess fat intake induces ectopic fat deposition in other tissues (Scherer \& Buettner 2011). Fatty liver may develop due to liver-related diseases such as steatosis, steatohepatitis, advanced fibrosis, cirrhosis, and cancer in addition to insulin resistance (Benedict \& Zhang 2017). Future studies are needed to determine whether or not NPGL participates in these processes. In contrast, the mass of interscapular BAT increased in mice fed a high-calorie diet. We are presently investigating the effect of NPGL on the function of BAT.

The present findings show that energy consumption and locomotor activity decreased after chronic infusion of NPGL under both standard chow and high-calorie diet conditions. It is possible that these decreases may contribute to fat accumulation in WAT by NPGL in mice. These findings are consistent with studies of orexigenic factors such as NPY, AgRP, and ghrelin, neurochemicals that also decrease energetic output, and anorexigenic factors such as $\alpha$-MSH and leptin that cause increased energy output (Schwartz et al. 2000). Sympathetic nerve activity is involved in these phenomena (Ramadori et al. 2011, Shi et al. 2013) as WAT and BAT are innervated by the sympathetic nerve, and increased sympathetic activation promotes lipolysis, energy consumption, thermogenesis, and locomotor activity (Bamshad et al. 1998, Oldfield et al. 2002, Kajimura \& Saito 2014, Dodd et al. 2015, Ryu et al. 2015). The paraventricular nucleus, suprachiasmatic nucleus, medial preoptic area, ventromedial hypothalamus (VMH), dorsomedial hypothalamus (DMH), lateral hypothalamus, and arcuate nucleus in the hypothalamus all control sympathetic nerve activity to promote homeostasis (Bamshad et al. 1998, Oldfield et al. 2002, Ryu et al. 2015). We have recently observed that NPGLcontaining neuronal fibers project to the $\mathrm{VMH}$ and $\mathrm{DMH}$ (Matsuura et al. 2017), suggesting that NPGL may decrease energy consumption and locomotor activity through suppression of sympathetic nerve activity. In addition, 
NPGL-containing fibers were found in close anatomical contact with POMC neurons in the hypothalamus (Matsuura et al. 2017), suggesting that NPGL may partially stimulate feeding behavior and/or fat accumulation through the inhibition of anorexigenic/catabolic POMC neurons. In the present study, NPY mRNA expression was decreased by NPGL, whereas AgRP, POMC and GAL mRNA were not altered. This outcome may be due to the negative feedback actions of leptin resulting from increased WAT. Future studies are necessary to elucidate the mechanism of NPGL action in the hypothalamus more precisely.

In conclusion, chronic infusion of NPGL regulates feedingbehavior, lipidmetabolism, respiratorymetabolism, and locomotor activity in mice. These results suggest that dysregulation of NPGL contributes to obesity through reductions in energy output and locomotor activity while concomitantly stimulating food intake and fat synthesis/ uptake, especially under high-calorie conditions. These findings, combined with previous studies, point to NPGL as a key hypothalamic regulator of feeding and energy metabolism and as a potential therapeutic target for the treatment/prevention of obesity and metabolic disease. Likewise, we found that NPGL mRNA is expressed in the brain of human (Iwakoshi-Ukena et al. 2017). Thus, future studies of NPGL in humans are warranted to assess the relationship between the biological activity of human NPGL and its pathophysiological status.

\section{Supplementary materials}

This is linked to the online version of the paper at https://doi.org/10.1530/ JOE-19-0112.

\section{Declaration of interest}

The authors declare that there is no conflict of interest that could be perceived as prejudicing the impartiality of the research reported.

\section{Funding}

This work was supported by JSPS KAKENHI Grant (JP26291066, JP15KK0259, and JP19H03258 to K U, JP16K07440 and JP19K06768 to E I-U, and JP18H06199 to K S), Grant-in-Aid for JSPS Fellows (15J03781 to $\mathrm{K} \mathrm{S}$ ), the Mishima Kaiun Memorial Foundation (K U and E I-U), the Urakami Foundation for Food and Food Culture Promotion ( $K \cup$ and E I-U), the Kao Research Council for the Study of Healthcare Science (K U), the Takeda Science Foundation (K U), the Food Science Institute Foundation (K U) and the Shiseido Female Researcher Science Grant (E I-U).

\section{Acknowledgements}

The authors are grateful to Ms Haruna Goto for experimental support and Dr Akiko K Satoh (Hiroshima University) for confocal microscopy.

\section{References}

Alberti KG, Eckel RH, Grundy SM, Zimmet PZ, Cleeman JI, Donato KA, Fruchart JC, James WP, Loria CM, Smith SC Jr, et al. 2009 Harmonizing the metabolic syndrome: a joint interim statement of the International Diabetes Federation Task Force on Epidemiology and Prevention; National Heart, Lung, and Blood Institute; American Heart Association; World Heart Federation; International Atherosclerosis Society; and International Association for the Study of Obesity. Circulation 120 1640-1645. (https://doi.org/10.1161/ CIRCULATIONAHA.109.192644)

Ameer F, Scandiuzzi L, Hasnain S, Kalbacher H \& Zaidi N 2014 De novo lipogenesis in health and disease. Metabolism: Clinical and Experimental 63 895-902. (https://doi.org/10.1016/j. metabol.2014.04.003)

Bamshad M, Aoki VT, Adkison MG, Warren WS \& Bartness TJ 1998 Central nervous system origins of the sympathetic nervous system outflow to white adipose tissue. American Journal of Physiology 275 R291-R299. (https://doi.org/10.1152/ajpregu.1998.275.1.R291)

Benedict M \& Zhang X 2017 Non-alcoholic fatty liver disease: an expanded review. World Journal of Hepatology 9 715-732. (https://doi. org/10.4254/wjh.v9.i16.715)

Dodd GT, Decherf S, Loh K, Simonds SE, Wiede F, Balland E, Merry TL, Münzberg H, Zhang ZY, Kahn BB, et al. 2015 Leptin and insulin act on POMC neurons to promote the browning of white fat. Cell 160 88-104. (https://doi.org/10.1016/j.cell.2014.12.022)

Ekkekakis P, Vazou S, Bixby WR \& Georgiadis E 2016 The mysterious case of the public health guideline that is (almost) entirely ignored: call for a research agenda on the causes of the extreme avoidance of physical activity in obesity. Obesity Reviews 17 313-329. (https://doi. org/10.1111/obr.12369)

Gomori A, Ishihara A, Ito M, Mashiko S, Matsushita H, Yumoto M, Ito M, Tanaka T, Tokita S, Moriya M, et al. 2003 Chronic intracerebroventricular infusion of $\mathrm{MCH}$ causes obesity in mice. Melanin-concentrating hormone. American Journal of Physiology. Endocrinology and Metabolism 284 E583-E588. (https://doi. org/10.1152/ajpendo.00350.2002)

Halaas JL, Boozer C, Blair-West J, Fidahusein N, Denton DA \& Friedman JM 1997 Physiological response to long-term peripheral and central leptin infusion in lean and obese mice. PNAS 94 8878-8883. (https://doi.org/10.1073/pnas.94.16.8878)

Heilig M \& Murison R 1987 Intracerebroventricular neuropeptide Y suppresses open field and home cage activity in the rat. Regulatory Peptides 19 221-231. (https://doi.org/10.1016/0167-0115(87)90278-3)

Huo L, Gamber K, Greeley S, Silva J, Huntoon N, Leng XH \& Bjørbaek C 2009 Leptin-dependent control of glucose balance and locomotor activity by POMC neurons. Cell Metabolism 9 537-547. (https://doi. org/10.1016/j.cmet.2009.05.003)

Iwakoshi-Ukena E, Shikano K, Kondo K, Taniuchi S, Furumitsu M, Ochi Y, Sasaki T, Okamoto S, Bentley GE, Kriegsfeld LJ, et al. 2017 Neurosecretory protein GL stimulates food intake, de novo lipogenesis, and onset of obesity. eLife 6 e28527. (https://doi.org/10.7554/eLife.28527)

Iyengar S, Li DL \& Simmons RM 1999 Characterization of neuropeptide Y-induced feeding in mice: do Y1-Y6 receptor subtypes mediate feeding? Journal of Pharmacology and Experimental Therapeutics 289 1031-1040.

Jhanwar-Uniyal M, Beck B, Jhanwar YS, Burlet C \& Leibowitz SF 1993 Neuropeptide Y projection from arcuate nucleus to parvocellular division of paraventricular nucleus: specific relation to the ingestion of carbohydrate. Brain Research 631 97-106. (https://doi. org/10.1016/0006-8993(93)91192-U)

Kajimura S \& Saito M 2014 A new era in brown adipose tissue biology: molecular control of brown fat development and energy homeostasis. Annual Review of Physiology 76 225-249. (https://doi.org/10.1146/ annurev-physiol-021113-170252) https://joe.bioscientifica.com https://doi.org/10.1530/JOE-19-0112
(C) 2020 Society for Endocrinology Published by Bioscientifica Ltd. Printed in Great Britain 
Kessler RC, Berglund PA, Chiu WT, Deitz AC, Hudson JI, Shahly V, Aguilar-Gaxiola S, Alonso J, Angermeyer MC, Benjet C, et al. 2013 The prevalence and correlates of binge eating disorder in the world health organization world mental health surveys. Biological Psychiatry $\mathbf{7 3}$ 904-914. (https://doi.org/10.1016/j.biopsych.2012.11.020)

Krasnow SM, Fraley GS, Schuh SM, Baumgartner JW, Clifton DK \& Steiner RA 2003 A role for galanin-like peptide in the integration of feeding, body weight regulation, and reproduction in the mouse. Endocrinology 144 813-822. (https://doi.org/10.1210/en.2002220982)

Livak KJ \& Schmittgen TD 2001 Analysis of relative gene expression data using real-time quantitative PCR and the $2^{-\Delta \Delta C t}$ method. Methods $\mathbf{2 5}$ 402-408. (https://doi.org/10.1006/meth.2001.1262)

Lusk G 1928 The Elements of the Science of Nutrition, 4th ed. Philadelphia, PA, USA: WB Saunders Company.

Masuda K, Ooyama H, Shikano K, Kondo K, Furumitsu M, Iwakoshi-Ukena E \& Ukena K 2015 Microwave-assisted solid-phase peptide synthesis of neurosecretory protein GL composed of 80 amino acid residues. Journal of Peptide Science 21 454-460. (https://doi.org/10.1002/psc.2756)

Matsuura D, Shikano K, Saito T, Iwakoshi-Ukena E, Furumitsu M, Ochi Y, Sato M, Bentley GE, Kriegsfeld LJ \& Ukena K 2017 Neurosecretory protein GL, a hypothalamic small secretory protein, participates in energy homeostasis in male mice. Endocrinology 158 1120-1129. (https://doi.org/10.1210/en.2017-00064)

Morley JE, Hernandez EN \& Flood JF 1987 Neuropeptide Y increases food intake in mice. American Journal of Physiology 253 R516-R522. (https://doi.org/10.1152/ajpregu.1987.253.3.R516)

Nakazato M, Murakami N, Date Y, Kojima M, Matsuo H, Kangawa K \& Matsukura S 2001 A role for ghrelin in the central regulation of feeding. Nature 409 194-198. (https://doi.org/10.1038/35051587)

Okamoto S, Sato T, Tateyama M, Kageyama H, Maejima Y, Nakata M, Hirako S, Matsuo T, Kyaw S, Shiuchi T, et al. 2018 Activation of AMPK-regulated CRH neurons in the PVH is sufficient and necessary to induce dietary preference for carbohydrate over fat. Cell Reports $\mathbf{2 2}$ 706-721. (https://doi.org/10.1016/j.celrep.2017.11.102)

Oldfield BJ, Giles ME, Watson A, Anderson C, Colvill LM \& McKinley MJ 2002 The neurochemical characterisation of hypothalamic pathways projecting polysynaptically to brown adipose tissue in the rat. Neuroscience 110 515-526. (https://doi.org/10.1016/S03064522(01)00555-3)

Patel SR, Murphy KG, Thompson EL, Patterson M, Curtis AE, Ghatei MA \& Bloom SR 2008 Pyroglutamylated RFamide peptide 43 stimulates the hypothalamic-pituitary-gonadal axis via gonadotropin-releasing hormone in rats. Endocrinology 149 4747-4754. (https://doi. org/10.1210/en.2007-1562)

Primeaux SD, Blackmon C, Barnes MJ, Braymer HD \& Bray GA 2008 Central administration of the RFamide peptides, QRFP-26 and QRFP43, increases high fat food intake in rats. Peptides 29 1994-2000. (https://doi.org/10.1016/j.peptides.2008.07.024)

Ramadori G, Fujikawa T, Anderson J, Berglund ED, Frazao R, Michán S, Vianna CR, Sinclair DA, Elias CF \& Coppari R 2011 SIRT1 deacetylase in SF1 neurons protects against metabolic imbalance. Cell Metabolism 14 301-312. (https://doi.org/10.1016/j.cmet.2011.06.014)

Rossi M, Beak SA, Choi SJ, Small CJ, Morgan DG, Ghatei MA, Smith DM \& Bloom SR 1999 Investigation of the feeding effects of melanin concentrating hormone on food intake--action independent of galanin and the melanocortin receptors. Brain Research 846 164-170. (https://doi.org/10.1016/S0006-8993(99)02005-3)
Ryu V, Garretson JT, Liu Y, Vaughan CH \& Bartness TJ 2015 Brown adipose tissue has sympathetic-sensory feedback circuits. Journal of Neuroscience 35 2181-2190. (https://doi.org/10.1523/ JNEUROSCI.3306-14.2015)

Scherer T \& Buettner C 2011 Yin and Yang of hypothalamic insulin and leptin signaling in regulating white adipose tissue metabolism. Reviews in Endocrine and Metabolic Disorders 12 235-243. (https://doi. org/10.1007/s11154-011-9190-4)

Schwartz MW, Woods SC, Porte D Jr, Seeley RJ \& Baskin DG 2000 Central nervous system control of food intake. Nature $\mathbf{4 0 4} 661-671$. (https:// doi.org/10.1038/35007534)

Shi YC, Lau J, Lin Z, Zhang H, Zhai L, Sperk G, Heilbronn R, Mietzsch M, Weger S, Huang XF, et al. 2013 Arcuate NPY controls sympathetic output and BAT function via a relay of tyrosine hydroxylase neurons in the PVN. Cell Metabolism 17 236-248. (https://doi.org/10.1016/j. cmet.2013.01.006)

Shikano K, Iwakoshi-Ukena E, Kato M, Furumitsu M, Bentley GE, Kriegsfeld LJ \& Ukena K 2019 Neurosecretory protein GL induces fat accumulation in chicks. Frontiers in Endocrinology 10 392. (https://doi. org/10.3389/fendo.2019.00392)

Shikano K, Kato M, Iwakoshi-Ukena E, Furumitsu M, Matsuura D, Masuda K, Tachibana T, Bentley GE, Kriegsfeld LJ \& Ukena K 2018 Effects of chronic intracerebroventricular infusion of neurosecretory protein GL on body mass and food and water intake in chicks. General and Comparative Endocrinology 256 37-42. (https://doi.org/10.1016/j. ygcen.2017.05.016)

Takayasu S, Sakurai T, Iwasaki S, Teranishi H, Yamanaka A, Williams SC, Iguchi H, Kawasawa YI, Ikeda Y, Sakakibara I, et al. 2006 A neuropeptide ligand of the $G$ protein-coupled receptor GPR103 regulates feeding, behavioral arousal, and blood pressure in mice. PNAS 103 7438-7443. (https://doi.org/10.1073/pnas.0602371103)

Tang-Christensen M, Vrang N, Ortmann S, Bidlingmaier M, Horvath TL \& Tschöp M 2004 Central administration of ghrelin and agouti-related protein (83-132) increases food intake and decreases spontaneous locomotor activity in rats. Endocrinology 145 4645-4652. (https://doi. org/10.1210/en.2004-0529)

Teegarden SL, Scott AN \& Bale TL 2009 Early life exposure to a high fat diet promotes long-term changes in dietary preferences and central reward signaling. Neuroscience 162 924-932. (https://doi. org/10.1016/j.neuroscience.2009.05.029)

Tempel DL, Leibowitz KJ \& Leibowitz SF 1988 Effects of PVN galanin on macronutrient selection. Peptides 9 309-314. (https://doi. org/10.1016/0196-9781(88)90265-3)

Ukena K 2018 Avian and murine neurosecretory protein GL participates in the regulation of feeding and energy metabolism. General and Comparative Endocrinology 260 164-170. (https://doi.org/10.1016/j. ygcen.2017.09.019)

Ukena K, Iwakoshi-Ukena E, Taniuchi S, Bessho Y, Maejima S, Masuda K, Shikano K, Kondo K, Furumitsu M \& Tachibana T 2014 Identification of a cDNA encoding a novel small secretory protein, neurosecretory protein GL, in the chicken hypothalamic infundibulum. Biochemical and Biophysical Research Communications 446 298-303. (https://doi. org/10.1016/j.bbrc.2014.02.090)

Wren AM, Small CJ, Ward HL, Murphy KG, Dakin CL, Taheri S, Kennedy AR, Roberts GH, Morgan DG, Ghatei MA, et al. 2000 The novel hypothalamic peptide ghrelin stimulates food intake and growth hormone secretion. Endocrinology 141 4325-4328. (https:// doi.org/10.1210/endo.141.11.7873)

Received in final form 12 September 2019

Accepted 18 September 2019

Accepted Manuscript published online 18 September 2019 https://joe.bioscientifica.com https://doi.org/10.1530/JOE-19-0112 (c) 2020 Society for Endocrinology Published by Bioscientifica Ltd. Printed in Great Britain 